\title{
Carpal tunnel syndrome and work organisation in repetitive work: a cross sectional study in France
}

A Leclerc, P Franchi, M F Cristofari, B Delemotte, P Mereau, C Teyssier-Cotte, A Touranchet, and the Study Group on Repetitive Work ing tools. ${ }^{1} 57811-16$ An association with forceful movements is less often found. ${ }^{14}$ Experimental studies bring additional arguments in favour of a causal relation between ergonomic factors and CTS. ${ }^{817}$ Carpal tunnel syndrome is generally considered to occur more often among women. Personal risk factors are being overweight, several medical disorders such as rheumatoid arthritis, metabolic disorders, thyroid disease, and for women, hormonal changes and a history of gynaecological surgery. ${ }^{72}{ }^{14}$ Other factors are less specific to CTS: an association with psychological factors is often found, as it is for most musculoskeletal disorders. ${ }^{18-20}$ Psychosocial factors at work play an important part. These involve several possible mechanisms including an increase in vulnerability to mechanical stress, effects on pain perception, and the capacity to cope with the illness. ${ }^{17}{ }^{20-24}$ At worker level, job control, which includes the possibility of having breaks and modifying the work pace has an effect on the intensity and the temporal changes in the physical constraints. At management level, constraints on the company lead to increasing productivity which in turn may increase the frequency of cumulative trauma disorders. ${ }^{2}$ To enhance their competitiveness, the companies implement new management practices such as "just in time" production systems ${ }^{3}$ which may add to the constraints of the workers; with this system, goods are produced just in time to be sold and materials are purchased just in time to be transformed. As there is no buffer to create "breathing spaces" a greater pressure for production can be expected. Other constraints on the company, such as a high level of competition, or dependency as a subcontractor, might have similar negative health effects. In 1993-4, a large cross sectional study on musculoskeletal disorders of the arm was carried out in France to gain a better understanding of the determinants of these disorders in repetitive work, with a special interest in the role of macrodeterminants at a company level. The preliminary results on shoulder pain, carpal tunnel syndrome, and epicondylitis have been presented. ${ }^{25}$ The results presented here focus on carpal tunnel syndrome.

\section{Material and methods}

\section{POPULATION, QUESTIONNAIRES}

This cross sectional survey was carried out in different branches of activity that at national level often had compensation for cumulative trauma disorders. These were: assembly line; clothing and shoe industry; food industry; and supermarket cashiers. It was planned to have \begin{abstract}
occupations and industries-for example, assembly workers; food industry, especially meat and fish processing; garment industry; boot and shoe manufacturing; supermarket cashiers; and use of video display terminals. ${ }^{2-10}$ Different dimensions of exposure to physical work load are widely recognised as risk factors rapid hand motions, repetitive bending and twisting of the hands and the wrist, fast work pace, repetitive grasping with the fingers, mechanical

stress at the base of the palm, and use of vibrat-
\end{abstract}

Accepted 18 September 1997 
more than 1500 subjects, a fifth of them being in a control group of non-repetitive work. In six regions (Lorraine, Pays de Loire, Rhône-Alpes, Centre, Basse-Normandie, Ile-de-France) occupational physicians in charge of workers in these branches were contacted through the network of "médecins inspecteurs" employed by the Ministry of Labour. A total of 39 occupational physicians participated. Each of them established a list of about 50 workers, 40 exposed to repetitive work and 10 controls. The selection criteria in both groups were based on the characteristics of the job. If the numbers were too large, a random sample was drawn on the basis of the month of birth. There were only two main exclusion criteria: in the exposed group, a change in working conditions in the past six months due to upper limb disorders; in the control group, the present employment being a consequence of previous upper limb disorder. Workers employed $<50 \%$ of normal working time were also excluded. The 40 exposed subjects were drawn from one to five working situations, defined as subgroups experiencing the same working conditions at a common work location - for example, the same workshop, or the same assembly line. The working situations had to be as homogeneous as possible for the working conditions. If needed, an ergonomist helped the occupational physician to define these subgroups. Most subjects belonged to only one working situation. A few shared their working time between several working situations. Subjects in the control group were mostly in the same company as the exposed subjects and were selected from occupational groups with a level of education comparable with the exposed subjects but with less repetitive tasks, such as maintenance, cleaning, or catering. These workers were not classified into working situations. There was no individual matching between exposed and unexposed subjects. However, the occupational physicians were asked to keep the same sex ratio in both groups, as far as possible. Each worker in the study was asked by the occupational physician to come alone to the consulting room. He or she completed a self administered questionnaire which was checked with the physician for the part about working conditions. The worker then underwent a standardised physical examination. The results of the examination were recorded on the medical questionnaire by the physician. Some questions on working conditions were included in the self administered questionnaire. Other questions, for exposed people only, came from a third questionnaire dealing with the working situations, which was filled in by the occupational physician at group level. It included detailed questions on the production system in the relevant sectors of the firm. It was completed with the help of the appropriate department in the company, and an ergonomist in each region. One or two regional meetings with the occupational physicians and the ergonomists took place before the survey. This enabled the study design and the questionnaires to be discussed. Training for the standardised physical examination was in- cluded in these meetings. The questionnaires were centralised and checked both at regional and national levels. An ergonomist (PF) reviewed all the questionnaires on the working situation. A specialist in occupational medicine (CTC) reviewed the medical part of the most complicated questionnaires. A few subjects did not participate. The reasons were changes in working conditions or departure from the company before the interview $(n=29)$, absence at the time of the interview $(n=28)$, or refusal $(n=30)$. Finally, 1757 workers took part in the overall study, including a control group of 337 . In this paper, supermarket cashiers $(n=210)$ were not included, as some aspects of the management practice-such as just in time production - and also variables - such as the cycle time-are not defined in this group. Hence, the results are based on 1547 subjects. The 1210 workers in repetitive work were classified into four activity sectors, one of them being packaging as some postural constraints and gestures were specific to this task. The four sectors were as follows:

- Assembly line in manufacturing of small electrical appliances, motor vehicle accessories, ski accessories, packaging excluded $(n=479)$

- Clothing and shoe industry, without packaging $(n=264)$

- Food industry (most of these workers were employed in the meat industry), packaging excluded $(n=307)$

- Packaging: among the 160 subjects in this category, 148 were employed in packaging in the food industry.

Table 1 describes the sample. The workers in repetitive work belonged to 111 different subgroups with homogeneous working conditions (working situations table 1). The percentage of women differed according to the sector, ranging from $25 \%$ in the food industry, packaging excluded, to $94 \%$ in the assembly line. The level of education was low in all the subgroups. In the food industry and packaging, workers were relatively young; most of them had worked for between one and 10 years at the present job. In the clothing and shoe industry, they were older and more than $60 \%$ had been in the same job for $>10$ years. In the assembly line subgroup, they were relatively old $(57.5 \%$ age $\geqslant 40$ years) but only $26 \%$ had had the present job for the past 10 years.

\section{CASE DEFINITION}

Carpel tunnel syndrome was considered to be present if Tinel's sign or Phalen's test was positive at the medical examination, or if a definite diagnosis based on nerve condition velocity had been established before the medical examination. Tinel's sign is positive if a mild percussion at the wrist produces paraesthesia or pain in the hand. Phalen's test was positive if paraesthesia or numbness along the median nerve distribution was reported after passive flexion of the wrist for 60 seconds. The subgroup of subjects without CTS included a few workers who had a history of surgery for CTS, but negative Tinel's sign and Phalen's test. A definition based only on the results of the medical examination was preferred in this 
Table 1 Characteristics of the sample

\begin{tabular}{|c|c|c|c|c|c|c|}
\hline & Assembly line & $\begin{array}{l}\text { Clothing and } \\
\text { shoes }\end{array}$ & $\begin{array}{l}\text { Food } \\
\text { industry }\end{array}$ & Packaging & Controls & Total \\
\hline Subjects (n) & 479 & 264 & 307 & 160 & 337 & 1547 \\
\hline Working situations (n) & 36 & 25 & 36 & 14 & & \\
\hline Firms (n) & 14 & 11 & 17 & 11 & & \\
\hline Women (\%) & 94.1 & 88.3 & 24.8 & 83.7 & 69.1 & 72.8 \\
\hline \multicolumn{7}{|l|}{ Age $(\%)$ : } \\
\hline$\leqslant 29$ & 13.6 & 8.3 & 29.3 & 31.9 & 17.8 & 18.6 \\
\hline $30-39$ & 23.0 & 32.6 & 35.8 & 35.6 & 30.6 & 32.0 \\
\hline $40-49$ & 43.6 & 45.8 & 24.4 & 19.4 & 34.4 & 35.7 \\
\hline$\geqslant 50$ & 13.8 & 13.3 & 10.4 & 13.1 & 17.2 & 13.7 \\
\hline \multicolumn{7}{|l|}{ Number of years at the job (\%): } \\
\hline 1 & 15.2 & 4.9 & 3.9 & 6.2 & 4.1 & 7.9 \\
\hline $1-10$ & 58.9 & 34.5 & 55.4 & 63.1 & 57.3 & 54.1 \\
\hline$\geqslant 10$ & 25.9 & 60.6 & 40.7 & 30.6 & 38.6 & 38.0 \\
\hline \multicolumn{7}{|l|}{ Level of education (\%): } \\
\hline Primary & 57.1 & 48.9 & 37.7 & 44.4 & 32.2 & 45.1 \\
\hline Lower vocational & 19.2 & 25.8 & 38.4 & 25.0 & 27.2 & 26.5 \\
\hline Secondary or upper vocational & 23.7 & 23.3 & 23.9 & 30.6 & 40.6 & 28.4 \\
\hline
\end{tabular}

study to avoid relying partly on the same source - that is, worker - for the assessment of morbidity and occupational constraints.

VARIABLES IN THE STUDY

A list of potential risk factors for CTS was established. This included variables both at personal and group level. The list took into account both results from the scientific literature and specific hypotheses to tests.

\section{Personal variables}

- Sex

- Age, in four categories $(\leqslant 29 ; 30-39$; $40-49 ; \geqslant 50$ )

- Body mass index: normal (BMI <27); overweight (BMI $\geqslant 27,<31$ ); obesity (BMI $\geqslant 31$ )

- Psychological and psychosomatic wellbeing.

The variable was based on a set of eight questions on psychological and psychosomatic wellbeing, derived from Langner's screening questionnaire. ${ }^{26}$ Three categories were used: no problem $($ score $=0)$, some problems $($ score $=1$ or 2) problems (score 3-8).

Individual occupational factors (tables 1 and 2)

- Sector: assembly; clothes and shoes; food; packaging; control group

- Number of years at the job, three categories: $<1 ; 1-<10 ; \geqslant 10$ )

- Work satisfaction: a score of work satisfaction was calculated as the sum of positive answers in a list of seven, expressing satisfaction with the workstation, workload, variety of work, relations at work (in general), and with colleagues: subjects were classified as satisfied $($ score $\geqslant 5$ ) or unsatisfied (score $\leqslant 4$ )
- Job control: a score of 0-5 was calculated from answers in the self administered questionnaire about: the possibility of deciding about the time of breaks, additional short breaks (possible or not), the pace not dictated by the machine, the control (at least partial) of the quantity of work, the control (at least partial) of the work pace: two categories were used according to the score low level (zero to two positive answers) and high level (three to five positive answers)

- Postures and motions: different postures and motions were considered as potential risk factors, with two categories, repetitively versus not repetitively or never, according to the self administered questionnaire: press with the hand, grasp with force, pull, push, turn, and screw, working with the arm above the shoulder repeatedly or often

- Self declaration of use of vibrating tools (any frequency).

Occupational factors at group level

The following variables characterised the various working situations. They were defined only for subjects in repetitive work. Table 3 shows the frequency for 1079 subjects belonging to a single working situation and classified as exposed for $100 \%$ of their working time.

- Cycle time, in four categories $(\geqslant 1 \mathrm{~min}$; 30-59 s; 10-29 s; <10 s)

- Autonomy at the workstation: a score was calculated as the sum of the following items: work in an autonomous team $v$ assembly line; stationary workstation $v$ moving along the assembly line; manual supply of goods $v$ machine supply; manual discharge of goods $v$ by the machine; manual moving of goods $v$ by the machine; stocks between the work stations,

Table 2 Frequencies (\%) of individual working constraints

\begin{tabular}{|c|c|c|c|c|c|c|c|}
\hline & Assembly line & $\begin{array}{l}\text { Clothing and } \\
\text { shoes }\end{array}$ & $\begin{array}{l}\text { Food } \\
\text { industry }\end{array}$ & Packaging & $\begin{array}{l}\text { Total } \\
\text { exposed }\end{array}$ & Controls & Total \\
\hline $\mathrm{n}$ & 479 & 264 & 307 & 160 & 1210 & 337 & 1547 \\
\hline Unsatisfied with work & 44.7 & 26.9 & 38.4 & 35.0 & 37.9 & 20.2 & 34.1 \\
\hline Low job control & 48.4 & 11.7 & 65.8 & 68.8 & 47.5 & 14.8 & 40.4 \\
\hline Press with the hand ${ }^{\star}$ & 68.9 & 45.5 & 50.5 & 46.3 & 56.1 & 30.9 & 50.6 \\
\hline Grasp with force & 18.2 & 8.3 & 36.5 & 16.9 & 20.5 & 14.8 & 19.3 \\
\hline Pull $^{\star}$ & 45.1 & 47.4 & 72.0 & 45.6 & 52.5 & 43.6 & 50.6 \\
\hline Push $^{\star}$ & 52.4 & 37.9 & 46.6 & 71.3 & 50.3 & 41.8 & 48.4 \\
\hline Turn and screw ${ }^{\star}$ & 54.7 & 14.0 & 22.2 & 17.5 & 32.6 & 23.4 & 30.6 \\
\hline Arm above the shoulder $\dagger$ & 39.0 & 8.3 & 34.5 & 56.9 & 33.6 & 33.2 & 33.5 \\
\hline Vibrating tools $\ddagger$ & 32.6 & 6.1 & 10.1 & 1.3 & 16.9 & 5.9 & 14.5 \\
\hline
\end{tabular}

^ Repeatedly; $\dagger$ often or repeatedly; $\ddagger$ any frequency. 
Table 3 Frequencies (\%) of group level occupational constraints

\begin{tabular}{|c|c|c|c|c|c|}
\hline & Assembly line & $\begin{array}{l}\text { Clothing and } \\
\text { shoes }\end{array}$ & Food industry & Packaging & Total exposed \\
\hline $\mathrm{n}^{\star}$ & 452 & 241 & 261 & 125 & 1079 \\
\hline \multicolumn{6}{|l|}{ Cycle timet: } \\
\hline$\geqslant 1 \mathrm{mn}$ & 15.3 & 48.1 & 36.1 & 16.0 & 27.9 \\
\hline $30-59 \mathrm{~s}$ & 29.2 & 21.6 & 11.0 & 7.2 & 20.4 \\
\hline $10-29 \mathrm{~s}$ & 29.9 & 14.9 & 16.9 & 37.6 & 24.2 \\
\hline$<10 \mathrm{~s}$ & 25.7 & 2.5 & 32.2 & 34.4 & 23.0 \\
\hline Low level of autonomy at the workstation & 42.8 & 15.8 & 64.7 & 52.0 & 43.0 \\
\hline Just in time production & 69.4 & 69.3 & 66.3 & 45.6 & 65.8 \\
\hline \multicolumn{6}{|l|}{ External constraints on the firm: } \\
\hline High level & 59.3 & 70.5 & 41.2 & 33.6 & 54.4 \\
\hline Very high level & 18.8 & 4.2 & 43.1 & 16.0 & 21.0 \\
\hline
\end{tabular}

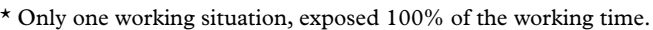

† Cycle time not defined for 73 subjects among the 1079 (missing values or multiple answers).

yes or no: two categories were used low autonomy (sum $\leqslant 2$ ), and high autonomy (sum $\geqslant 3$ )

- Just in time production (yes or no), which characterises the production system of the company

- External constraints on the company: subcontractor; high level of competitiveness; production of seasonal goods; production of perishable foodstuffs (use by time $<1$ week): a three category score was based on these variables $($ sum $=0$ or $1 ; 2 ; 3$; or 4$)$.

MEDICAL CONDITIONS

Several medical conditions possibly associated with CTS were recorded: rheumatoid arthritis, diabetes, thyroid problems, gout, neurological illness, wrist accident in the past, and for women, use of oral contraceptives, pregnancy, menopause, and ovariohysterectomy. None of these conditions was associated with CTS in this study, except ovariohysterectomy in women. However, as this condition was infrequent, it was not taken into account in the analyses.

METHODS

The differences in frequency of CTS between exposed and unexposed subjects and the role of the risk factors were studied mainly with logistic models, with BMDP software. ${ }^{27}$ The analysis was developed in three steps: firstly, the various sectors were compared with the control group, taking into account personal, nonoccupational factors (logistic model 1). In the second step the role of the most usually studied risk factors was examined. The variables in logistic model 2 included all the potential risk factors indicated in the variables in the study except autonomy at the workstation, just in time production, and external constraints on the company. This part of the analysis was restricted to subjects in repetitive work in the same working condition for $100 \%$ of their time $(n=1079)$. The objective was to get a more precise view on the determinants of CTS within the subgroup of workers exposed to repetitive work. Sector was included in the model because preliminary analyses indicated that sector was an independant risk indicator of CTS, reflecting underlying risk factors not taken into account by other variables. As the hypothesis that risk factors at a group level (autonomy at the workstation, just in time production, and external constraints on the company) played a part could be considered as a new hypothesis, we examined this aspect only in a third step. The associations between these three variables, between them and CTS, and between them and the other occupational factors including cycle time were examined. This, and the comparison between logistic models with and without these variables, allowed a more precise appraisal of whether the associations between CTS and the production constraints at company level were entirely mediated through other factors such as cycle time or job control. For logistic models, a backward stepwise modelling strategy was used. At the first step, the model included all the possible determinants of CTS. At each step, nonsignificant terms $(\mathrm{p}>0.15)$ were removed, except age and sex which were kept in the model. As well as age and sex, the final model included factors associated with CTS at $\mathrm{p}<0.15$.

\section{Results}

FREQUENCY OF CTS

A total of 151 cases of CTS were present in one or both hands in $11.8 \%$ of workers in repetitive work and $2.4 \%$ of those in the control group (table 4). The frequency was especially high in packaging $(16.2 \%)$. In the food industry, except packaging, it was lower than in the assembly line subgroup or in the clothing and shoe industry, but it remained higher than in the control group. The right side was more affected in all sectors. The frequency of bilateral CTS was especially high in packaging. The sixth column of table 4 (exposed not $100 \%$ or several working conditions) comprises 131 subjects in repetitive work who either worked in repetitive work $<100 \%$ of the time, or worked in repetitive work $100 \%$ of the time but in several working situations. All these subjects were exposed to repetitive work more than $50 \%$ of their working time. In this group the frequency of CTS was similar to that of the whole group of exposed workers. Special attention was given to the eight subjects with CTS in the control group. It was found that two of them had sequellae of CTS surgery (women of 40 and 47 years employed as cleaners). Two men were not completely unexposed, as their pace was dictated by the machine. Another man had been exposed until 1991 (boning, in the meat industry). One had thyroid disease. For the two remaining cases, nothing particular was identified. 
Table 4 Frequency of carpal tunnel syndrome

\begin{tabular}{|c|c|c|c|c|c|c|c|c|c|}
\hline Number (\%) & $\begin{array}{l}\text { Assembly } \\
\text { line }\end{array}$ & $\begin{array}{l}\text { Clothing } \\
\text { and shoes }\end{array}$ & $\begin{array}{l}\text { Food } \\
\text { industry }\end{array}$ & Packaging & $\begin{array}{l}\text { Repetitive work } \\
100 \% \text {, only one } \\
\text { working } \\
\text { condition }\end{array}$ & $\begin{array}{l}\text { Repetitive work } \\
\text { not } 100 \% \text { or } \\
\text { several working } \\
\text { conditions }\end{array}$ & $\begin{array}{l}\text { Repetitive } \\
\text { work total }\end{array}$ & Controls & Total \\
\hline $\begin{array}{l}\mathrm{n}^{\star} \\
\text { Subjects with }\end{array}$ & 479 & 264 & 307 & 160 & 1079 & 131 & 1210 & 337 & 1547 \\
\hline CTS & $64(13.4)$ & $32(12.1)$ & $21(6.8)$ & $26(16.2)$ & $130(12.0)$ & $13(9.9)$ & $143(11.8)$ & $8(2.4)$ & 1519.8 \\
\hline CTS right side & $55(11.5)$ & $25(9.5)$ & $19(6.2)$ & $22(13.7)$ & $110(10.2)$ & $11(8.4)$ & $121(10.0)$ & $6(1.8)$ & 1278.2 \\
\hline CTS left side & $30(6.3)$ & $17(6.4)$ & $10(3.3)$ & $17(10.6)$ & $69(6.4)$ & $5(3.8)$ & $74(6.1)$ & $5(1.5)$ & 795.1 \\
\hline CTS both sides & $21(4.4)$ & $10(3.8)$ & $8(2.6)$ & $13(8.1)$ & $49(4.5)$ & $3(2.3)$ & $52(4.3)$ & $3(0.9)$ & 553.6 \\
\hline
\end{tabular}

* Subjects in repetitive work are classified both according to the sector and according to the number of working conditions.

PERSONAL FACTORS AND DIFFERENCES BETWEEN SECTORS

Table 5 shows the results of the first model, including personal, non-occupational factors, and sector. Five variables were included: sex, age, body mass index, psychological and psychosomatic wellbeing, and the sector. The final model included all the five variables. Psychological wellbeing was strongly associated with CTS, with a gradient according to the intensity of problems. Body mass index was a risk factor, the risk being higher for a BMI $\geqslant 27$. Age was not a significant factor. However, subjects aged $\geqslant 30$ years tended to have a higher risk. The odds ratio (OR) for women was $>1$, but the association with sex was not significant. Taking into account these variables, strong differences between sectors were found. The ORs were significantly different from 1 and higher than 3 in the four sectors of repetitive work. It was especially high in packaging. Thus, the results presented in table 4 were confirmed by the model.

INDIVIDUAL OCCUPATIONAL FACTORS AND CYCLE TIME

The next model (model 2, table 6) included 12 occupational factors (sector, number of years at the job, work satisfaction, job control, use of vibrating tools, cycle time, and six motion variables listed in the methods section). The four personal factors were the same as in model 1 , except that only two categories for BMI were distinguished $(\mathrm{BMI}<27 ; \quad \mathrm{BMI} \geqslant 27)$. The model was restricted to subjects for whom cycle time could be defined, and who were

Table 5 Factors associated with carpal tunnel syndrome, logistic model 1; personal factors and sector, 1547 subjects, 151 cases

\begin{tabular}{|c|c|c|c|}
\hline & p Value & OR & $(95 \% C I)$ \\
\hline Sex: & 0.1121 & & \\
\hline Male & & 1 & \\
\hline Female & & 1.58 & (0.89 to 2.83$)$ \\
\hline Age: & 0.4041 & & \\
\hline$\leqslant 29$ & & 1 & \\
\hline $30-39$ & & 1.21 & (0.69 to 2.14 ) \\
\hline $40-49$ & & 1.55 & (0.89 to 2.70$)$ \\
\hline$\geqslant 50$ & & 1.22 & (0.63 to 2.39$)$ \\
\hline Sector: & $<10^{-4}$ & & \\
\hline Controls & & 1 & \\
\hline Assembly & & 4.54 & (2.27 to 9.09 ) \\
\hline Clothing & & 4.12 & (1.95 to 8.71 ) \\
\hline Food & & 3.14 & (1.38 to 7.15$)$ \\
\hline Packaging & & 6.55 & (3.02 to 14.2 ) \\
\hline Psychology: & 0.0016 & & \\
\hline No problem & & 1 & \\
\hline Some problems & & 1.36 & (0.91 to 2.04$)$ \\
\hline Problems & & 2.32 & (1.48 to 3.63$)$ \\
\hline BMI: & 0.0018 & & \\
\hline$<27$ & & 1 & \\
\hline$\geqslant 27$ to $<31$ & & 2.16 & (1.35 to 3.45$)$ \\
\hline$\geqslant 31$ & & 1.91 & (1.09 to 3.37$)$ \\
\hline
\end{tabular}

exposed to repetitive work $100 \%$ of their working time. Thus, the model excluded the 337 subjects from the control group, the 131 workers who were exposed for $<100 \%$ of the time or those exposed in several working conditions, and the 73 with missing values (or multiple answers) to cycle time. This led to a total of 1006 subjects in the model. The final model included five of the 12 occupational factors, with $\mathrm{p}$ values between 0.05 and 0.15 . Some differences between sectors remained. A low level of job control and dissatisfaction at work were risk factors of CTS. One motion, pressing repeatedly with the hand, was a risk factor. For cycle time, a gradient was found from an $\mathrm{OR}=1$ in the control category ( $\geqslant 1 \mathrm{~min}$ ) to $\mathrm{OR}=1.9$ for a cycle time $<10 \mathrm{~s}$.

ROLE OF AUTONOMY AT THE WORKSTATION, JUST IN TIME PRODUCTION, AND EXTERNAL CONSTRAINTS ON THE FIRM

Bivariate associations

The production constraints at company level were not independent, but none of them was a strong determinant of the others. The OR between just in time production and low autonomy at the workstation calculated on the 1006 subjects was 1.93. For external constraints on the firm, taking the low level as a control category, the ORs with just in time production were 2.37 for the medium level and 3.13 for the high level. The corresponding ORs measuring the relation with low autonomy at the workstation were 1.29 and 2.08. In the group of 1006 subjects exposed to repetitive work, and without a missing value for cycle time, neither autonomy at the workstation nor external constraints on the firm were associated with CTS; just in time production increased the frequency of CTS, with an unadjusted OR of 1.67; just in time production was not strongly associated with other risk factors from logistic model 2. The percentage of workers in the just in time category ranged from $43 \%$ in packaging to $74 \%$ in the clothing and shoe industry. A U shaped relation with cycle time was found, with a higher frequency of just in time production in extreme categories $(>1$ $\mathrm{min}$ or $<30 \mathrm{~s}$ ). Work satisfaction was not associated with just in time production. The relation with job control was not in the expected direction; among the 676 subjects classified in the just in time category, $41 \%$ had a low level of job control. The percentage was $61 \%$ for the other workers. 
Table 6 Factors associated with carpal tunnel syndrome, logistic models 2 and 3, 1006 subjects, 127 cases

\begin{tabular}{|c|c|c|c|c|c|c|}
\hline & \multicolumn{3}{|c|}{ Model $2 \dagger$} & \multicolumn{3}{|c|}{ Model $3 \ddagger$} \\
\hline & $p$ Value & $O R$ & $(95 \% C I)$ & p Value & $O R$ & $(95 \% C I)$ \\
\hline Sex: & 0.2592 & & & 0.1651 & & \\
\hline Male & & 1 & & & 1 & \\
\hline Female & & 1.49 & (0.73 to 3.04$)$ & & 1.65 & (0.80 to 3.42$)$ \\
\hline Age: & 0.1724 & & & 0.1355 & & \\
\hline$\leqslant 29$ & & 1 & & & 1 & \\
\hline $30-39$ & & 1.85 & (0.91 to 3.76$)$ & & 1.93 & (0.95 to 3.95$)$ \\
\hline $40-49$ & & 2.11 & (1.05 to 4.22$)$ & & 2.20 & (1.09 to 4.44$)$ \\
\hline$\geqslant 50$ & & 1.71 & (0.77 to 3.82$)$ & & 1.71 & (0.76 to 3.83$)$ \\
\hline BMI: & 0.0005 & & & 0.0003 & & \\
\hline$<27$ & & 1 & & & 1 & \\
\hline$\geqslant 27$ & & 2.16 & (1.41 to 3.29$)$ & & 2.23 & (1.46 to 3.40$)$ \\
\hline Psychology: & 0.0048 & & & 0.0040 & & \\
\hline No problem & & 1 & & & 1 & \\
\hline Some problems & & 1.15 & (0.73 to 1.82$)$ & & 1.16 & (0.74 to 1.82$)$ \\
\hline Problems & & 2.32 & (1.40 to 3.82$)$ & & 2.34 & (1.42 to 3.85$)$ \\
\hline Sector: & 0.0732 & & & 0.0865 & & \\
\hline Assembly & & 1 & & & 1 & \\
\hline Clothing & & 1.64 & (0.93 to 2.91$)$ & & 1.25 & (0.74 to 2.12$)$ \\
\hline Food & & 0.62 & (0.28 to 1.36$)$ & & 0.64 & (0.29 to 1.40$)$ \\
\hline Packaging & & 1.43 & (0.78 to 2.61$)$ & & 1.78 & (0.98 to 3.25$)$ \\
\hline Work satisfaction: & 0.0877 & & & & & \\
\hline Yes & & 1 & & & Not is & final model \\
\hline No & & 1.42 & (0.95 to 2.11$)$ & & & \\
\hline Press with the hand: & 0.1085 & & & 0.1356 & & \\
\hline No & & 1 & & & 1 & \\
\hline Yes & & 1.41 & (0.92 to 2.15$)$ & & 1.37 & (0.90 to 2.09$)$ \\
\hline Job control: & 0.1110 & & & 0.0322 & & \\
\hline High & & 1 & & & 1 & \\
\hline Low & & 1.43 & (0.92 to 2.23 ) & & 1.59 & (1.04 to 2.43$)$ \\
\hline Cycle time: & 0.1449 & & & & & \\
\hline$\geqslant 1 \mathrm{~min}$ & & 1. & & & & \\
\hline $30-59 \mathrm{~s}$ & & 1.03 & (0.56 to 1.89$)$ & & Not is & final model \\
\hline $10-29 \mathrm{~s}$ & & 1.33 & (0.75 to 2.37 ) & & & \\
\hline$<10 \mathrm{~s}$ & & 1.90 & (1.04 to 3.48 ) & & & \\
\hline Just in time ${ }^{\star}$ & & & & 0.0004 & & \\
\hline No & & & & & 1 & \\
\hline Yes & & & & & 2.24 & (1.40 to 3.57$)$ \\
\hline
\end{tabular}

$\star$ Not included in model 2

† Not in the final model $(\mathrm{p}>0.15)$. Grasp with force, repeatedly; pull repeatedly; push repeatedly; turn and screw repeatedly; arm above shoulder often or repeatedly; use of vibrating tools; number of years at the job.

$\ddagger$ Not in the final model $(\mathrm{p}>0.15)$. Same as for model 2, plus: work satisfaction (individual); cycle time; autonomy at the workstation; external constraints on the firm.

\section{Multivariate analysis}

The role of the three production constraints at company level was studied with a logistic model including these variables at the first step as well as those in model 2 (model 3, table 6). Autonomy at the workstation and external constraints on the firm were included although they were not associated with CTS, to confirm these results with a multivariate approach.In the final model, CTS was associated with just in time production with an OR of 2.24. The associations with other variables were not greatly changed between models 2 and 3 . However, cycle time and satisfaction at work were no longer associated with the syndrome. A low level of job control remained a risk factor, with a $p$ value of 0.03 . A noticeable difference remained between packaging and food industry excluding packaging. Some negative results were common to models 2 and 3: CTS was not associated with the use of vibrating tools nor with forceful gestures-for example, repeatedly grasping with force. The number of years at the job was not a significant risk factor.

\section{Discussion}

The subjects in the study were not representative of the whole population in the selected industrial sectors; due to the constraints of the study, the companies in the study were mainly large or medium size firms. Also, most of the occupational physicians who participated were in charge of companies with a high level of cumulative trauma disorders. The large size of the survey and the variety of industrial sectors limited the assessment of occupational exposure. Occupational gestures were self assessed, which led to a lack of precision. Also, the same wording might reflect different gestures in different occupational situations. On the other hand, the study design enabled the inclusion of 53 companies from four industrial sectors, whereas many studies are limited to one company. This is an important point, as each place of work is specific, and it is difficult to generalise from a few working situations. Another positive aspect was the high response rate. The criteria for assessing CTS was based on a standardised physical examination by the occupational physician. In this study, the frequency of CTS was high compared with some other studies. ${ }^{1324}{ }^{28-30}$ However, it is recognised that the frequency of CTS has a large variability, depending both on the level and characteristics of exposure and the definition of the syndrome. ${ }^{8}$ In some studies, the frequency of CTS may be low because the work, although repetitive, does not involve frequent flexion or extension of the wrist or forceful gripping. ${ }^{24}$ The high frequency in the control group was not surprising given that the past and present level of exposure in this group was far from negligible. As a consequence, the OR associated with sectors in table 5, ranging 
from 3.14 in the food industry to 6.55 in packaging are underestimated. An additional underestimation might come from the healthy worker effect. ${ }^{31}$ Misclassification of case status may have happened, as Tinel's and Phalen's sign have been shown to have sensitivities in the range of $20 \%$ to $70 \%$ and specificities of $70 \%$ to $80 \% .^{32}$ However, differential misclassification was limited by the relatively objective nature of the test, especially among workers exposed to repetitive work, who were considered by the physician performing the physical examination as being equally exposed. The statistical analysis did not take into account the hierarchical nature of the data. For simplicity reasons, a logistic model was preferred to a multilevel model. ${ }^{33}$ According to comparisons made on similar data ${ }^{34} 35$ it can be hypothesed that the estimates of the ORs for cycle time (model 2) and just in time (model 3) are not biased. However, the precision of the ORs is overestimated. It must be noted that this problem is not specific to this study, as the assessment of postural constraints is often made at group level or based on the observation of typical work tasks. ${ }^{36}$ Backward stepwise model fitting is potentially very sensitive to the list of variables in the model and to the correlations between them. Simultaneous inclusion of closely related variables in the models was avoided, and the results were globally rather stable. ${ }^{25}$ However, extrapolations from these results need to be cautious, as the results are sensitive to the statistical methods, and also to the specificities of the variables and population of study. Limiting a large part of the analysis to subjects exposed to repetitive work was necessary to avoid strong correlations between occupational factors. The results can be interpreted in two steps: firstly, being exposed or not to repetitive work is a risk factor; secondly, within subjects exposed to repetitive work, the risk depends on the level of postural and organisational constraints. Results on personal factors, gestures, and repetitive work can be compared with results from other studies on CTS. Regarding personal factors, the study confirmed that body mass index is associated with the syndrome ${ }^{12}$ and that psychological wellbeing is a risk indicator. However, it is not clear whether existence of psychological problems is a causal factor or a consequence of the syndrome. In this study, a major risk factor was repetitive work. In some sectors such as packaging the risk was higher, although the cycle time was also taken into account. The assessment of cycle time at the workplace is not an easy task, especially when short subcycles are included in a longer cycle. Cycle time might not fully indicate the repetitiveness of the tasks. The role of some gestures - such as having to press with the hand-was highlighted in this study, in accordance with other authors. ${ }^{817} 21$ However, the association with CTS was not significant at $p<0.05$. We did not find an association with forceful movements or exposure to vibrations. ${ }^{72-14}$ Few people in this study had to handle vibrating tools. The negative results for forceful movements are not accounted for by the lack of statistical power in the study. One explanation may be that some aspects of force are associated with wrist tendinitis more than with CTS. Results for packaging in this study are consistent with high frequencies of CTS found in other studies. ${ }^{916}$ Repetitive bending of the wrist and repetitive grasping with the fingers might be especially prevalent in packaging. ${ }^{7}$ More generally, the role of sector in the models may reflect the role of other ergonomic or organisational exposures specific of each sector. A relation with the number of years at the job was not found. This might be due to the cross sectional design of the study, which is not well adapted to describe complex relations including both healthy worker effects and training (which might reduce the frequency of disorders with time) ${ }^{24}$ Other authors have found a higher risk for subjects with less years at that job. ${ }^{12}$ Results on the role of psychosocial stressors at work and control of the job are in accordance with other studies on upper limb musculoskeletal disorders. ${ }^{23}{ }^{24}$ 37-39 This result was not completely expected, as most studies on the role of psychosocial factors deal with unspecific disorders, and not with a specific diagnosis - such as CTS. An inverse relation between CTS and low level of job control as a consequence of CTS is unlikely, as the score was based on objective constraints - such as pace dictated by the machine. For that reason, the results reinforce the hypothesis that psychosocial factors may play an aetiological part rather than influence perception and reporting of pain. One of the objectives of the study was to explore the role of occupational constraints at a management level, which might act though an intensification of the work (or of the workpace), less control over the job, or other increases in psychosocial constraints reflected by dissatisfaction at work. The results of the role of just in time production seem to indicate that a high level of competition is a risk for the health of the workers. This result accords with results from non-industrial sectors that show the role of work load, time pressure, and the presumed role of the level of productivity in the companies. ${ }^{2}$ Demanding a decrease in productivity and competitiveness is unrealistic. Moreover, it would not be a sensible preventive strategy, as the relevant risk factors are not the production system itself, but intermediate factors such as control over work timing and other organisational factors at the worker level which may be a consequence of the just in time production system. ${ }^{3}$ In this study intermediate variables between just in time production and CTS could not been clearly identified, which reflects the fact that many factors account for the prevalence of CTS and also that the effects of constraints at the company level are insufficiently known. In conclusion, future studies should consider this question of the effects of production organisation and constraints at the company level. This suggestion fits in with more general recommendations from epidemiologists and health researchers ${ }^{40}{ }^{41}$ for putting more emphasis on determinants at the population or group level and also improving and 
popularising statistical methods adapted to these approaches. The study was conducted with financial support from ANACT,
INRS, and the Ministry of Labour. We thank professor LJ Fine, INRS, and the Ministry of Labour. We thank professor LJ Fine,
from CDC, Cincinnati, USA, for his help with the questionnaire from CDC, Cincinnati, USA, for his help with the questionnaire and comments on the first results. The Study Group on Repetitive Work consisted of: JF Chastang, MF Landre, I Niedhammer, and A Schmaus from INSERM U88, Paris; C Elia, J Honnet, A Jabes, and J Schram from ANACT, Paris; O Heran-Leroy
from DARES, Ministère du Travail, Paris; $M$ Gournay, G from DARES, Ministère du Travail, Paris; M Gournay, G Marignac, F Monestier, D Quinton, C Rondeau du Noyer, C Vallayer, and E Violette from Inspection Medicale du Travail; J Maline from JM Praxo, Paris; Y Roquelaure from CHU, Angers; with 39 occupational physicians: Drs Abele, Aboukhalil, Allard, Benoit, Bohème, Bouet-Sode, Boutet, Camus, Casagrande, Charlane, Cleyet-Merle, Court, Deutscher, Dubosc, Dufrenne, Dugied, Dupuy, Durant, Geraud, Gerbault, Kriegel, Labourel, Le Chevanton, Lecompte, Lefevre, Lisse, Lods, Mariel, Martin, Mangin, Paillette, Pinchon, Pohren, Ravonjison, Renault, Thiebault, Tobelem, Vaysse, Verhille, and Weber. We thank JM Faucheux, C Frisch, A Leclerc, P Laban, M Vignon, F Niquet, N Pelissier, P Pellegrin, and $M$ Tatah for their work at the regional level, and Nathalie Lopes for the administration of the project.

1 Hagberg M, Silverstein B, Wells $\mathrm{R}$, et al. Work related musculoskeletal disorders. London: Taylor and Francis, 1995.

2 musculoskeletal disorders. London: Taylor and Francis, 1995. work-related cumulative trauma disorders of the upper
extremities in the United States : an evaluation of possible extremities in the United States : an evaluation

3 Jackson PR, Martin R. Impact of just-in-time on job content, employee attitudes and well-being: a longitudinal study. Ergonomics 1996:39:1-16.

4 Yassi A, Sprout J, Tate R. Upper limb repetitive strain injuries in Manitoba. Am $\mathcal{F}$ Ind Med 1996;30:461-72.

5 Ohlsson K, Attewell R, Skerfving S. Self-reported symptoms in the neck and upper limbs of female assembly workers. Scand $\mathcal{F}$ Work Environ Health 1989;15:75-80.

6 Punnet L, Robins JM, Wegman DH, et al. Soft tissue disorders in the upper limbs of female garment workers. Scand $\mathcal{f}$ Work Environ Health 1985;11:417-25.

7 Tanaka S, Wild DK, Seligman PJ, et al. Prevalence and work-relatedness of self-reported carpal tunnel syndrome among US workers ; analysis of the occupational health among US workers ; analysis of the occupational health Am f Ind Med 1995;27:451-70.

8 Hagberg M, Morgenstern H, Kelsh M. Impact of occupations and job tasks on the prevalence of carpal tunnel syndrome. Scand $\mathcal{F}$ Work Environ Health 1992;18:337-45.

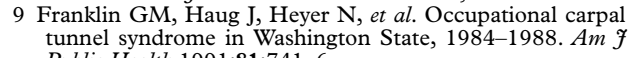
Public Health 1991;81:741-6.

10 Margolis W, Kraus JF. The prevalence of carpal tunnel syndrome symptoms in female supermarket checkers. $7 \mathrm{Occup}$ Med 1987;29:953-6.

11 Falck B, Aamio P. Left-sided carpal tunnel syndrome in butchers. Scand F Work Environ Health 1983;9:291-7.

12 Cannon LJ, Bernacki EJ, Walter SD. Personal and occupational factors associated with carpal tunnel syndrome. F Occup Med 1981;23,4:255-8.

13 Silverstein BA, Fine LJ, Armstrong TJ. Occupational factors and carpal tunnel syndrome. Am F Ind Med 1987;11:34358 .

14 Wieslander G, Norbäck D, Göthe CJ, et al. Carpal tunnel syndrome and exposure to vibration, repetitive wrist movesyndrome and exposure to vibration, repetitive wrist movement, and heavy manu

15 Barnhart S, Demers PA, Miller M, et al. Carpal tunnel syndrome among ski manufacturing workers. Scand $\mathcal{F}$ Work Environ Health 1991;17:46-52.

16 Masear VR, Hayes JM, Hyde AG. An industrial cause of carpal tunnel syndrome. F Hand Surg [Am] 1986;11:222-7.

17 Amstrong T, Buckle P, Fine L, et al. A conceptual model for work-related neck and upper limb musculoskeletal disorders. Scand F Work Environ Health 1993;19:73-84.
18 Leino PI, Hänninen V. Psychosocial factors at work in relation to back and limb disorders. Scand $\mathcal{f}$ Work Environ Health 1995;21:134-42.

19 Bongers PM, DeWinter CR, Kompier MAJ, et al. Psychosocial factors at work and musculoskeletal disease. Scand $\mathcal{F}$ Work Environ Health 1993;19:297-312.

20 Hagberg M. Neck and arm disorders. ABC of work related disorders. BMf 1996;313:419-22.

21 Scientific Committee for musculoskeletal disorders of the ICOH. Musculoskeletal disorders: work-related risk factors and prevention. Int f Occup Environ Health 1996;2-3:23946.

22 Theorell T, Harms-Ringdahl K, Ahlberg-Hulten G, et al. Psychosocial job factors and symptoms from the locomotor system. A multicausal analysis. Scand f Rehabil Med 1991; 23:165-173.

23 Marcus M, Gerr F. Upper extremity musculoskeletal symptoms among female office workers: associations with video display terminal use and occupational psychosocial stressors. Am f Ind Med 1996;29:161-70.

24 Ohlsson K, Attewell R, Palsson B, et al. Repetitive industrial work and upper limb disorders in females. Am f Ind Med 1995;27:731-47.

25 Affections péri-articulaires des membres supérieurs et organisation du travail. Résultats de l'enquête épidémiologique nationale. Documents pour le Médecin du Travail 1996;65:13-31.

26 Langner TS. A twenty-two item screening score of psychiatic symptoms indicating impairment. Fournal of Health and Human Behaviour 1962;3:269-76.

27 Dixon WJ, ed. BMDP statistical software. Berkeley: University of California Press, 1983.

28 Viikari-Juntura E. Neck and upper limb disorders among slauthterhouse workers: an epidemiologic and clinical study. Scand 7 Work Environ Health 1983;9:283-90.

29 Ohlsson K, Hansson GA, Balogh I, Strömberg U, et al. Disorders of the neck and upper limb in women in the fish processing industry. Occup Environ Med 1994;51:826-32.

30 Pale S, Boitel L, Demogeot F, et al. Résultats d'une enquête sur le syndrome du canal carpien en milieu professionnel. Arch Mal Prof 1992;53:473-4.

31 Punnet L. Adjusting for the healthy worker selection effect in cross-sectional studies. Int F Epidemiol 1996;25:1068-76.

32 Katz JN, Stirrat CR. A self-administered hand diagram for the diagnosis of carpal tunnel syndrome. $\mathcal{F}$ Hand Surgery [Am] 1990:15:360-3.

33 Goldstein H, Rasbash J. Improved approximations for multilevel models with binary methods. Fournal of the Royal Statistical Society A 1996;159:505-13.

34 Rodriguez G, Goldman N. An assessment of estimation procedures for multilevel models with binary responses. Fournal of the Royal Statistical Society A 1996;158:73-89.

35 Rabilloud M, Ecochard R, Matillon Y. Utilisation d'un modèle de régression logistique à deux niveaux dans l'analyse des variations de pratique médicale: à propos de la césarienne prophylactique. Rev Epidemiol Santé Publique 997:45:237-47.

36 Kilbom A. Assessment of physical exposure in relation to work-related musculoskeletal disorders. What information can be obtained from systematic observations? Scand $\mathcal{F}$ Work Environ Health 1994;20(special issue):30-45.

37 Bernard B, Sauter S, Fine L, et al. Job task and psychosocial risk factors for work-related musculoskeletal disorders among newspaper employees. Scand $\mathcal{F}$ Work Environ Health 1994;20:417-26.

38 Houtman ILD, Bongers PM, Smulders PGW, et al. Psychosocial stressors at work and musculoskeletal problems. Scand $\mathcal{f}$ Work Environ Health 1994;20:139-45.

39 Saurel-Cubizolles MJ, Bourgine M, Touranchet A, et al. Douleurs péri-articulaires des membres supérieurs et conditions de travail dans les abattoirs de volaille et les conserveries. Archives des Maladies Professionnelles 1992;53: $74-476$

40 Pearce N. Traditional epidemiology, modern epidemiology, and public health. Am $\mathcal{F}$ Public Health 1996;86,5:678-83.

41 Anonymous. Population health looking upstream. Lancet 1994;343:429-30 